\title{
MARLY DE OLIVEIRA E LYA LUFT: RECONSTRUINDO A SOLIDÃO INFANTIL
}

Angélica Soares (UFRJ)

RESUMO: Numa perspectiva feminista, focalizaremos poemas memorialísticos de Marly de Oliveira e Lya Luft, que recriam situações de medo e solidão experimentadas na infância. Partiremos do entendimento do dinamismo da memória, especialmente no que se refere ao tempo, ao sujeito recordador e à tensão entre as dimensões individual e social. O memorialismo poético será reconhecido como um modo de ficcionalização da tridimensionalidade temporal, de lembranças lacunares e do sujeito como mediador entre o passado e o presente, bem como ser projetado para o futuro. A indivisualização das lembranças constrói-se como uma metonímia, pois cada estória impõe-se como história do sistema educacional coercitivo, mais fortemente imposto à mulher pelo patriarcalismo e or uma concepção essencialista do gênero.

"O olho vê, a lembrança revê, e a imaginação transvê". (Manuel de Barros 1997: 75)

O verso antológico, em epígrafe, desse grande poeta brasileiro bem introduz a relação entre memória e poesia, com a qual trabalharemos. $\mathrm{O}$ ato de transvisão, que integra $\mathrm{o}$ ver, o rever e o imaginar, por se configurar como uma conceituação poética da memória, nos parece a melhor forma de compreendermos como se projeta, nos versos, o que ficou para trás e se tornou irresgatável, em sua realidade palpável.

Por outro lado, nosso ponto de partida para o entendimento do dinamismo da memória e sua reconstrução literária são ainda as formulações de Bergson, para quem a memóriahábito, resultante da repetição, junta-se à memória-recordação, ligada à representação, às imagens-lembranças, que consistem na emergência afetiva de acontecimentos, evocada por sensações que retornam renovadas (BERGSON 1990: 57-70).

A recriação de situações que se projetam da "memória-hábito" e/ou das "imagenslembranças" integra a ficcionalidade do memorialismo poético, pois, da reelaboração do passado desrealizado resulta o verossímil. Assim, tem o poeta liberdade para refazer o acontecido.

Marilena Chauí, por sua vez, chama-nos a atenção para o seguinte: "o que foi não é uma coisa revista por nosso olhar, nem é uma idéia inspecionada por nosso espírito - é o alargamento das fronteiras do presente..." (1987: xviiii). Desse modo, nossas recordações adquirem sempre um sentido que ultrapassa ao da revivência. Refazemos o passado ampliando o presente, que se abre ao vir-a-ser, numa tridimensionalidade que habita cada experiência, pensamento ou sentimento já vivenciado. Desse modo, o passado é revisto a partir da perspectiva antecipante do futuro, unindo-se o começo ao fim. Lembremos que Mnemósine referencia, no radical "mne", a unidade, ligando "o que foi, o que é e o que será” (ver VERNANT 1970: cap. II). 
Acrescentemos a essas breves reflexões introdutórias o fato de que, embora haja, no ato de lembrar, um "eu" que seleciona e dá relevo a determinados acontecimentos, há sempre na lembrança uma tensão entre o individual e o social, uma vez que ela depende de seus relacionamentos com a família, a classe social, a escola, a profissão, tornando-se possível o resgate de elementos, de estratégias e do dinamismo do sistema social, porquanto se reconstrói um passado com imagens e idéias que guardam em si a memória coletiva da sociedade. A memória de um indivíduo está ligada à do grupo e esta à tradição. Daí que a estoricização das proibições na infância, em que se recriam traumas e situações de solidão como experiências individualizadas, testemunha a história de um processo de educação, que é exatamente o contrário do sentido originário do ex-ducere, do conduzir para adiante, do fazer emergir as potencialidades físicas, morais e intelectuais da criança, na direção de uma constante pulsão de vida, sob os desígnios libertários de Eros.

No memorialismo poético de Marly de Oliveira, esse estado de coisas assim se denuncia:

Foi desde sempre, de início, esse registro de ventos, cruéis e frios, que vedam todo alvoroço e alegria, se algo novo se concerta. Não foi minha ama uma fera, pois sei que de humano tinha uma beleza concreta: uns olhos que de tão verdes luziam na luz aberta que entrava pelas janelas, portas, varandas, jardins, da minha casa deserta.

De minha infância deserta, onde não cabia o sonho e a hera crescia muda; onda não havia trégua entre o meu medo e o desânimo. (Nenhuma pergunta ousada!) No entanto, que infiltração de suspeitas infundadas criando mel com as abelhas de que mal se imaginava. Pois desde cedo assentado ficara que, filho e gado, pastariam onde apenas lhe fosse imposto ou deixado. (OLIVEIRA 1989: 437)

A infância rememorada alarga, no presente, o sentido da opressão e o da desertificação, que presidiam (presidem ainda) uma lógica de censura patriarcal, que "veda" o sonho e o prazer, pondo, em seu lugar, "o medo e o desânimo" sem tréguas. Práticas opressivas presidem o processo de adestramento que, nessa lógica, se confundem com ensinar e aprender. Reduplicam-se, a cada geração, no âmbito da família e da escola, estratégias de desumanização do infante, numa relação mútua entre técnicas de saber e de poder. $\mathrm{O}$ 
livre exercício da criatividade, próprio da vida da criança, se vê impedido pela ação de "ventos cruéis e frios", dirigidos pela atuação da "ama", alicerçada na aproximação ideologicamente predominante entre "filho e gado".

Embora essas memórias nos tragam uma perspectiva individualizadora ("minha infância"), elas nos apontam, metonimicamente, para o ideal burguês de manutenção da ordem e, com ela, do poder, assegurada por métodos apropriados de sanções, de exclusões, de seleção..., que garantem a sua permanência, pelo impedimento de contestação de suas verdades, o que no texto se indica parenteticamente "(Nenhuma pergunta ousada)".

Esse procedimento, dito educacional, mas coercitivo e amedrontador, como sabemos através de documentos históricos recentes, atua mais fortemente quando voltado para a menina, por visar à garantia da passividade, da submissão e da fragilidade, que lhe são incutidas, como qualidades próprias de sua natureza feminina, pelo sistema falocêntrico e essencialista de sexo-gênero (MOI 1989: 122-24).

O medo vivenciado na infância é também fonte e motivo da poesia de Lya Luft, onde se acrescenta o sentimento da morte, prematuramente experimentado pela criança, em decorrência da solidão. Senão vejamos:

No relógio daquelas madrugadas, quando eu era menina e estava insone, a velhinha do Tempo tricotava longas tiras de medo: minha morte ia sendo preparada nessa trama. Sedas, farrapos, teias tão soturnas, todo o terror que eu esquecia quando me libertavam sol e cores. Alguma coisa ficou daquelas noites: o metal dos ponteiros, as agulhas, as mãos ossudas das bruxas noturnas, tudo continua na urdidura do fio singular da minha sorte.

(LUFT 1984: 83)

Se anotarmos, mais uma vez, com Marilena Chauí, que o recordador "no que lembra e no como lembra, faz com que fique o que signifique" (1987: xxx), melhor poderemos avaliar quão significativo é trazer pela memória, da fase infantil para o presente, o mistério da morte. Ao invés do ingênuo e lúdico exercício vital, o que merece destaque, na infância, é o soturno e terrorífico "tricotar" da morte, pré-sentida no passado e conscientizada no presente da recordação. A leveza e o conforto do sono infantil, que seriam decorrentes da prática de uma liberdade sem medo, se vêem substituídos pela angústia, metaforizada nas "sedas", "farrapos" e "teias", com que a "velhinha do Tempo" produzia as "tiras de medo".

$$
* * *
$$

Inscrevendo-se como sujeito do discurso, denunciando o autoritarismo falocêntrico e pondo em questão a construção essencialista de identidades na transvisão memorialística, integradora do ver, do rever e do imaginar, a mulher escritora recria um 
olhar que, até quando inclui a instância do sonho, refaz o seu caráter políticodenunciatório.

Esses depoimentos literários da opressão na infância, por transporem através da dimensão social da memória, o universo de uma recordadora e por incluírem o futuro, posicionam a mulher frente ao todo de suas possibilidades.

Os movimentos feministas muito já avançaram, como sabemos, na modificação do status quo, atuando nas escolas, nas delegacias de mulheres, na medicina e, em especial, na psiquiatria e na psicanálise; mas muito ainda se tem a fazer para que as memórias das mulheres não estejam tão impregnadas da desertificação existencial e do terror, como as que selecionamos, entre tantas outras, para focalizar neste breve ensaio.

\section{OBRAS}

CITADAS:

BARROS, Manuel de. 1997. Livro sobre nada. Rio de Janeiro, Record. BERGSON, Henri. 1990. Matéria e memória. São Paulo, Martins Fontes. BOSI, Ecléa. 1987. Memória e sociedade; lembranças de velhos. 2. ed. São Paulo: T.A. Queiroz.

CHAUÍ, Marilena. 1987. "Os trabalhos da memória". Ecléa Bosi. Memória e sociedade; lembranças de velhos. 2. ed. São Paulo: T.A. Queiroz. xvii-xxxii. DE LAURETIS, Teresa. 1999. "A tecnologia do gênero." Heloisa Buarque de Hollanda, org.Tendências e impasses; o feminismo como crítica da cultura. Rio de Janeiro, Rocco, 1999.

p. 228.

LUFT, Lya. 1984. Mulher no palco. Rio de Janeiro, Salamandra. MOI, Toril. 1989. "Feminist, Female, feminine. Toril Moi et alii. The feminist reader. London: Macmillan.

117-132.

OLIVEIRA, Marly de. 1989. Obra poética reunida. São Paulo: Massao Ohno. SOARES, Angélica. 1999. "Memória poética feminina: hierarquias em questão." Christina Ramalho, org. Literatura e feminismo; propostas teóricas e reflexões críticas. Rio de Janeiro: 9lo. 91-105. —. 1999. "Memória e poesia: interrogando a identidade em Lya Luft, Helena Parente Cunha, Hilda Hilst e Marly de Oliveira." Cadernos de Letras (Rio de Janeiro) 14: 106111.

VERNANT, Jean-Pierre. 1990. Mito e pensamento entre os gregos. 2 ed. Rio de Janeiro: Paz e Terra. 